\title{
Consumption of antibiotics in Greenland, 1964-1970 II. Effect of coincidental administration of antibiotics on early syphilitic infections
}

\author{
GUNNAR AAGAARD OLSEN \\ Treponematoses Department, Statens Seruminstitute, Copenhagen, Denmark
}

It is well known that Treponema pallidum is sensitive to the antibiotics most commonly used. If antibiotic treatment is given to a patient with unrecognized syphilitic infection the course of the disease will therefore be modified. Attention has so far been paid particularly to the effect of treatment for gonorrhoea on syphilitic infections. Moore (1956), Schamberg (1956, 1963), Willcox (1962), and Danehower and Schamberg (1963) have stated that the total use of drugs in a community must be assumed to have an important effect on the incidence of syphilis.

By comparing the reported drug consumption in Greenland with that in Scandinavia (Olsen, 1973), an estimate may be made of the extent to which early syphilitic infections may be affected by treatment with antitreponemal antibiotics in the doses generally used. The effect up to the end of the secondary stage is of particular epidemiological importance, since a curative effect on unrecognized syphilitic infections will mean both that the case is not diagnosed, and that the spread of infection is prevented or limited.

No attempt is made in the present study to evaluate the effectiveness of the antibiotic treatment generally used in diagnosed cases of syphilis; the aim is to illustrate the expected but coincidental effects on syphilis of antibiotics given for other conditions.

\section{Evaluation}

The effect of antibiotics on syphilis is dependent on the stage of the infection (Eagle, Magnuson, and Fleischman, 1947; Moore, Mahoney, Schwartz, Sternberg, and Wood, 1944; Mahoney, Arnold, Sterner, Harris, and Zwally, 1944). The dosage is also important (Moore and others, 1944; Turner and Hollander, 1957), and particularly the duration of a suitable drug concentration in the serum. The time during which an antitreponemal drug concentration needs to be maintained in the organism to achieve a cure in the primary stage of infection is not precisely

Received for publication July, 71972 established. It has been demonstrated by experiments in rabbits that 400 units penicillin per $\mathrm{kg}$. injected intramuscularly five times at 3-hrly intervals either aborts the infection or prolongs the incubation period (Magnuson and Eagle, 1945). The smaller the experimental inoculum and the sooner the penicillin was given during the incubation period, the larger was the proportion of lesions completely suppressed. By the time clinical and/or serological evidence of syphilis has developed in a patient, curative levels of penicillin need to be maintained for much longer periods (Moore and others, 1944; Hallinger, 1968). Thus, one injection of 300,000 units PAM, which provides an effective serum concentration for 3 or 4 days, will cure most cases of seronegative primary syphilis but will be ineffective in cases of seropositive primary and secondary syphilis (Cutler, Olansky, and Price, 1955). For the latter 2.4 m.u. PAM was considered adequate by Perdrup (1948).

Olansky, Hogan, Taggart, Landman, and Robin (1950) and Taggart, Romansky, and Landman (1952) reported the results of treatment with aureomycin and chloramphenicol by mouth. Using $60 \mathrm{mg}$. per $\mathrm{kg}$. per day for 6 to 8 days, the results were comparable to those obtained using $300,000 \mathrm{u}$. or more of penicillin per day for $7 \frac{1}{2}$ to 10 days. When the dosage was in the range of 30 to $240 \mathrm{mg}$. $/ \mathrm{kg}$./day given for 4 days or less, the results were poor. It has been demonstrated clinically and experimentally that these broad-spectrum antibiotics have a much weaker antitreponemal action than penicillin (reviewed by Luger, 1962, 1968). The time during the course of the infection at which the curative effect of a standard course of treatment with tetracycline is replaced by various degrees of modification cannot be stated, but this must be expected to occur earlier than with penicillin treatment.

\section{Coincidental effects}

The main antitreponemal effects arising from the use of antibiotics can thus be classified into three types, 
each with a characteristic effect on the epidemiology of syphilis:

(1) Effects arising from the treatment of gonorrhoeal infections with penicillin preparations.

(2) Effects arising from the treatment of non-venereal infections with penicillin preparations.

(3) Effects arising from the treatment of non-venereal infections with tetracycline.

(1) With penicillin or ampicillin treatment of gonorrhoeal infections, the antitreponemal concentrations will generally last about 16 to 24 hours, so that a cure of syphilitic infections can be expected only if they are in the incubation phase. Whether such treatment cures all syphilitic infections in the incubation phase is not yet known and the results must be expected to vary according to the type of treatment. When clinical or serological signs of syphilis are present, it is likely that the treatment of gonorrhoea will modify the course of the syphilitic infection rather than cure it. However, if a proper examination is carried out, the syphilis will have been diagnosed. Modification of the course of syphilitic infection by the treatment of gonorrhoea with penicillin can then be expected particularly when clinical and serological examinations are inadequate, e.g. in areas with limited medical facilities, such as Greenland.

(2) Penicillin or ampicillin treatment for 3 to 4 days can be expected to cure many undiagnosed cases of early syphilitic infection, even though such treatment does not provide the same margin of safety as that recommended in the case of diagnosed early syphilis. (3) If treatment with tetracycline is given for a non-venereal infection for 3 to 4 days, a cure can probably be expected only if the concurrent syphilis is in the incubation phase. After this, such treatment will generally lead to a modification of the clinical and serological course of the disease.

\section{Epidemiological considerations}

Moore (1956) thought the decreasing frequency of syphilis observed at the beginning of the 1950 s to be largely the result of coincidental treatment of unrecognized syphilitic infections with penicillin. Schamberg $(1956,1963)$ and Danehower and Schamberg (1963) supported this theory and considered the increase in the incidence of syphilis seen after 1955-56 to be due to changes in the pattern of antibiotic usage. On the basis of the quantities of penicillin and broad-spectrum drugs manufactured in the U.S.A. and the changes in the doses used in the treatment of bacterial infections, they concluded that the number of courses of treatment with penicillin decreased after 1955, while the number of treatments with broadspectrum drugs seemed to have doubled from 1953 to 1960 . Thus, the chances that an early syphilitic infection would be exposed to a coincidental curative effect seemed to be decreasing, while the possibility of a subcurative effect was increasing during that period.

After 1960, and especially after 1965, the pattern of antibiotic consumption changed again, and oral ampicillin preparations were used more frequently, leading to a relative decrease in the consumptior of tetracycline (Olsen, 1973). Thus, penicillin and ampicillin have been dominant in recent years, although tetracycline products still constitute a considerable part of the total consumption. More syphilis infections should be cured by the coincidental effect of the present use of antibiotics than in the period in which tetracycline dominated, but the number will be less than in the early 1950 s.

When strongly treponemicidal drugs were first used in the treatment of gonorrhoea, a change in the epidemiological relationship between gonorrhoea and syphilis was observed. As demonstrated by Keldbeck and Marcussen (1952), the incidence of syphilis in patients with gonorrhoea and of gonorrhoea in patients with syphilis decreased in a direct ratio with the increasing use of penicillin treatment for venereological infections from 1946 to 1949 .

As mentioned by Danehower and Schamberg (1963), the important effect of 'happenstance' treatment lies not only in the fact that syphilitic infections may be cured, but also in the fact that many other infections may be prevented, because the period of infectiousness of the early syphilis cases which have been exposed to this influence are shortened or eliminated. Danehower and Schamberg (1963) illustrated the spread of syphilis with and without the 'happenstance' factor according to the antibiotic consumption in the U.S.A. in the 1950s. They calculated a hypothetical decrease of 8.4 per cent. in new cases when the 'happenstance' effect was included, instead of a 3.4 per cent. increase without it. The cumulative effect, calculated over several 'generations', was a 30 per cent. decrease in the course of one year.

If the theoretical calculations of Danehower and Schamberg are applied to the figures for antibiotic consumption and the incidence of syphilis in Denmark, it appears that without 'happenstance' treatment at least twice as many cases of early syphilis as were actually observed could have been expected in Denmark in the 1960s. In Greenland the effect will have been even greater.

The public health authorities in Greenland were of the opinion, until recently, that there were no unknown syphilis carriers among the resident population (Lomholt and Berg, 1966; Olsen, 1966). In the few cases diagnused, it was demonstrated that 
the infection came from outside (except for one case of tertiary syphilis-Medicinalberetning, 1947). Socalled epidemics, in which the original infection was introduced from abroad, have occurred (Helms, 1894; Marcussen and Rendal, 1950; Olsen, 1966) but, because of the comprehensive control measures, it was considered that there were no unknown syphilitic infections in the population. In the 'epidemics' of 1947 and 1965, cases of syphilis were observed which were modified by drugs prescribed for other infections, particularly gonorrhoea. Furthermore, these courses of treatment seem to have limited the spread of infection and also to have made the detection of the sources of infection more difficult.

In a region such as Greenland, where a high incidence of bacterial infections necessitates a particularly frequent use of antibiotics, the suppression of unrecognized syphilitic infections would be expected to be even greater than in Denmark proper. With the present facilities for discovering the sources of syphilitic infection in Greenland, the modification of clinical and serological evidence of syphilis caused by antibiotic treatment creates diagnostic problems (Jørgensen, personal communication; Knudsen, personal communication).

\section{Summary and conclusions}

Treponema pallidum is sensitive to the antibiotics most generally used. Since the consumption of these drugs is increasing on a global scale, more coincidental effects on unrecognized syphilitic infections are to be expected.

Penicillin treatment for gonorrhoea and other conditions is more likely to lead to both cure and limitation of the spread of the infection in cases of early syphilis than treatment with tetracycline, which may only modify such cases. However, modified infections may also be found after the treatment of gonorrhoea with penicillin or ampicillin in cases in which clinical or serological evidence of early infection remains undetected, which is likely to happen in areas where medical facilities are limited. Therefore, as regards the incidence of diagnosed syphilis in an area and the occurrence of syphilis infections modified by the use of antibiotics, the amounts and the types used, changes in usage, and available medical facilities may be of great significance.

The cumulative effect of the widespread use of antibiotics on the infectiousness of cases of early syphilis has probably reduced the number of cases of early syphilis in Denmark by more than 50 per cent. In Greenland, the more frequent use of antibioticsespecially for gonorrhoea-has led to even greater coincidental effects on the incidence of syphilis than in Denmark.

\section{References}

Cutler, J. C., Olansky, S., and Price, E. V. (1955) Arch. Derm. (Chicago), 71, 239

D.A.K. (1971) Personal communication D.A.K. Laboratories, Denmark

(1972) Idem

Danehower, W. F., and Schamberg, I. L. (1963) Arch. Derm. (Chicago), 88, 930

Eagle, H., Magnuson, H. J., and Fleischman, R. (1947) f. exp. Med., 85, 423

Hallinger, L. (1968) Acta derm.-venereol. (Stockh.), 48, 260

Helms, O. (1894) Ugeskr. Laeg., 5th ser., 1, 265

Jørgensen, B. B. (1972) Personal communication

Keldbeck, L., and Marcussen, P. V. (1952) Acta derm.venereol. (Stockh.), 32, 193

Knudsen, E. A. (1972) Personal communication

Lomholt, G. and BERG, O. (1966) Brit. F. vener. Dis., 42, 1

LugER, A. (1962) 'Syphilistherapie' in 'Handbuch der Haut und Geschlechtskrankheiten'. ed. J. Jadassohn, 'Erganzlingswerk', VI/2, p. 1583. Springer, Berlin

- (1968) 'Antibiotic Treatment of Venereal Diseases', Curr. Probl. Derm., ed. A. Luger, vol. 2, p. 58. Karger, Basel

Magnuson, H. J., and Eagle, H. (1945) Amer. F. Syph., 29, 587

Mahoney, J. F., Arnold, R. C., Sterner, B. L., Harris, A., and Zwally, M. R. (1944) F. Amer. med. Ass., 126, 63.

Marcussen, P. V., and Rendal, J. (1950) Amer. f. Syph., 34, 144

MEDICINALBERETNING (1947) Kongeriget Danmark, Sundhedsstyrelsen, 262, Kbh.

MOORE, J. E. (1956) Brit. F. vener. Dis., 32, 217

-, Mahoney, J. F., Schwartz, W. Sternberg, T., and Wood, W. B. (1944) F. Amer. med. Ass., 126, 67

Olansky, S., Hogan, R. B., TAGgart, S. R., LANDMan, G. S., and Robin, E. D. (1950) Amer. F. Syph., 34, 436

OLSEN, G. Aa. (1966) Ugeskr. Laeg., 128, 1071 (1973) Brit. F. vener. Dis., 49, 20

Perdrup, A. (1948) Nord. Med., 38, 710

Schamberg, I. L. (1956) Arch. Derm. (Chicago), 73, 523 (1963) Brit. F. vener. Dis., 39, 87

TAGgart, S. R., Romansky, M. J., and LANDMAN, G. S. (1952) Amer. F. Syph., 36, 174

TURNer, T. B., and Hollander, D. H. (1957) 'Biology of the Treponematoses'. WHO Monograph Ser., No. 35

Willcox, R. R. (1962) Brit. F. vener. Dis., 38, 189 